\title{
NEUROTOXICIDADE DO ALUMÍNIO NA DOENÇA DE ALZHEIMER
}

\section{Beatriz Lopes Tecedor Bassi ${ }^{1}$ \\ Wendel Simões Fernandes ${ }^{2}$ \\ Simone Aparecida Biazzi de Lapena ${ }^{3}$}

Resumo: A relação entre o alumínio (Al) e a doença de Alzheimer (DA) é foco de diversas pesquisas realizadas ao longo dos séculos XX e XXI. Muitas teorias e observações foram desenvolvidas dividindo a comunidade científica em grupos de cientistas a favor e contra a ideia de que o Al pode ser um fator desencadeante ou influenciável no desenvolvimento ou piora da doença. A partir de uma revisão dos trabalhos realizados sobre esta relação, deseja-se discutir os diferentes pontos de vista relacionados à toxicidade do alumínio na DA. Pôde-se perceber que há grande divergência entre os autores em relação a tópicos, como contaminações e suas vias de entrada. De acordo com o presente estudo, percebeu-se que houve divergências porque a etiologia da doença não foi totalmente elucidada. Portanto, para melhor esclarecimento da neurotoxicidade, fazem-se necessários estudos mais aprofundados das regiões do cérebro e dos fenômenos químicos e bioquímicos do SNC.

Palavras-chave: Alumínio; Doença de Alzheimer; Memória; Neurotoxicidade.

\footnotetext{
${ }^{1}$ Discente do curso de Farmácia/UNIP, Brasil. E-mail: bea.tecedor@hotmail.com.

2 Docente do curso de Farmácia/UNIP, Brasil. E-mail: wen_sfernandes@hotmail.com.

${ }^{3}$ Coordenadora do curso de Farmácia/UNIP, Brasil. E-mail: simone_lapena@yahoo.com.br.
} 